\title{
Heart Rate and Blood Pressure Trait of Bangladeshi Children Age Ranged from 1 to 12 Years
}

\author{
Anup Adhikari ${ }^{1, *}$, Nahida Pervin ${ }^{2}$ \\ ${ }^{1}$ Anthropometrica, Toronto, Canada \\ ${ }^{2}$ Bangladesh Institute of Sports (BKSP), Dhaka, Bangladesh \\ *Corresponding author: dranupadhikari@yahoo.com
}

\begin{abstract}
Received August 20, 2014; Revised August 29, 2014; Accepted September 10, 2014
Abstract Blood pressure of Bangladeshi children aged between 1 to 12 from both sexes were measured in Bangladesh. Three hundred and seventy one children were measured randomly for their heart rate and blood pressure, out of which 243 were boys and 128 were girls. In the present study height and weight were increased gradually as age increases. Both systolic and diastolic pressure elevated gradually as age advanced though the change was not highly significant. Similar observations were also noticed when both boys and girls were analysed separately. Thus heart rate gradually decreases significantly as age, height and weight increases whereas both systolic and diastolic blood pressure increases as age, height and weight increases.
\end{abstract}

Keywords: heart rate, blood pressure, children, age, height, weight

Cite This Article: Anup Adhikari, and Nahida Pervin, "Heart Rate and Blood Pressure Trait of Bangladeshi Children Age Ranged from 1 to 12 Years.” American Journal of Sports Science and Medicine, vol. 2, no. 5A (2014): 29-33. doi: 10.12691/ajssm-2-5A-7.

\section{Introduction}

Blood pressure or arterial blood pressure is one of the principal vital signs for human being irrespective of children and adult. The incidence of obesity in children is increasing worldwide, primarily in urbanized, highincome countries, and hypertension development is a detrimental effect of this phenomenon. Very little works has been done on children as children does affected so much except in obese condition. As the obesity rate in children increasing tremendously and there is a risk of hypertension in obese children, more and more importance was given on children's blood pressure study. According to World Health Organisation (WHO), obesity in children is not only a problem of developed countries, it has same impact on the developing and poor countries too due to change of food habit and life style of urban people [1].

As early as the first decades of this century, blood pressure was investigated in children and young adults $[2,3,4]$. These studies revealed that average level of blood pressure in childhood increases with age. Since then, virtually all studies of blood pressure in children, performed in variety of populations, have shown a rise of blood pressure with age [5,6,7]. Childhood obesity has become a severe health problem, especially during the last few decades. In fact, the prevalence of overweight and obesity has been increased over the last years in the Western countries. Therefore, the increasing numbers of obese children and adolescents all over the world demand an investment in the primary and secondary prevention of obesity and overweight in this age group which is related with high blood pressure among the children [8,9] Arterial hypertension is a major health risk in virtually all age group from childhood to adult. Thus, study group of WHO has given more stress on epidemiological research into hypertension both in children and adult [1].

Bangladesh is a developing country where developing urbanisation and life style changes has an impact on the children health risk factors especially on the cardiovascular diseases risk factors. No such studies has been done on blood pressure and pulse rate in children age range from 1 to 12 years especially on children with lower age group. The aim of the present study was to assess the heart rate and blood pressure of Bangladeshi children from childhood to adolescence to emphasize the need for further research on the etiology and prevention of hypertension. It was a pilot study to review further research on children of same age group.

\section{Method}

\subsection{Study Population}

371 children were measured randomly for their heart rate and blood pressure from local primary health care centre at Savar, a suburban area near Dhaka, Bangladesh. Most of the them were from low socio-economic group as the primary health care centre was for made for these group of peoples. Out of 371 children, 243 were male and 128 were female. The age range was from 1 year to 12 years.

\subsection{Stature}


Stature was measured with an anthropometric rod and with an anthropometric tape according the method followed by International Society for the Advancement of Kinanthropometry (ISAK) protocol [10]. Children below 2 years who could not stand erectly, were measured in lying position. Children were placed on a table in lying position on their back and height was measured with an Anthropometrical tape from feet to vertex. Two to three trials were taken during the measurement to avoid error. Children aged from 2 to 12 years were measured in standing position.

\subsection{Weight}

Body weight was measured using platform type electronic weighing scale so that children below 2 years could be placed on the weighing base pan to get correct body weight.

\subsection{Heart Rate}

Heart rate was measured from feeling the carotid artery in one minute with an electronic stop watch.

\subsection{Blood Pressure}

Blood pressure was measured with standard Ausculatory method [11,12] using mercury sphygmomanometer. Special care and attention was taken for the children and correct cuff was used according to size of the upper arm of the children. To cover the age range of 1-12 years, three different sizes of cuffs were used, with bladder dimensions $4 \times 13 \mathrm{~cm}, 10 \times 18 \mathrm{~cm}$ and $12 \times 26 \mathrm{~cm}$. While measuring the blood pressure, more emphasis was given on the length of the bladder so that the bladder encircle minimum 80 of the arm circumference.

\subsection{Ethical Issues}

While designing and conducting the study, emphasis was given on ethical issues related to children and their parents.

\subsection{Statistical Analysis}

Statistical analysis was done with the Statistical package SPSS 11.0 and Sigma Plot.

\section{Results}

Table 1 showed the physical characteristic, heart rate and blood pressure of 371 children combined. Average values for all parameters of each age group was shown in the table.

Table 2 showed the physical characteristics, heart rate and blood pressure of male participants.

Table 3 showed the physical characteristics, heart rate and blood pressure of female participants.

Table 4, Table 5 and Table 6 represented the correlation coefficient (r) values when all the parameters were correlated among themselves.
Figure 1, Figure 2 and Figure 3 were the graphical representations between age and heart rate, weight and heart rate and height and heart rate.

\section{Discussion}

In young adult, pressure in the aorta and in the brachial and other large arteries rises to a peak value (systolic pressure) of about $120 \mathrm{mmHg}$ during each heart cycle and fails to a minimum value (diastolic pressure) of about 70 $\mathrm{mmHg}$. The blood pressure in the brachial artery in young adult in sitting position at rest is approximately $120 / 70$ $\mathrm{mmHg}$ for systolic and diastolic respectively. There is a general agreement that blood pressure with advancing age, but magnitude of this rise is uncertain because hypertension is a common disease and its incidence increases with advancing age [12].

In children normal blood pressure depends on several factors like age, height and weight. According to US Department of Health Services, taller children possess higher normal blood pressure than the children with less height [13]. In the present study, when all the children, irrespective of their gender were considered, were possessed low systolic blood pressure compare to other studies in all ages (Table 1 ). The minimum mean systolic pressure observed for 1 year age group was $69.1 \pm 8.3$ $\mathrm{mmHg}$ whereas that of for 12 year age group was $95.9 \pm$ $5.6 \mathrm{mmHg}$. All the values for other age groups were lying in between these two average values (Table 1). Very similar observations were observed for systolic blood pressure when boys and girls were considered separately (Table 2 and Table 3). A minimum average value of 66.7 $\pm 8.2 \mathrm{mmHg}$ for systolic pressure was observed for 1 year age group whereas a maximum average value of 96.1 \pm 5.7 was observed for 12 year age group. All other age groups' average values for systolic pressure were lying in between 66.7 and $96.1 \mathrm{mmHg}$ (Table 2). For the girls, minimum average systolic value for 1 year age group was observed to be $72.3 \pm 7.9$ which was slightly higher than the same age boys group, but the maximum average value was $95.5 \pm 5.5 \mathrm{mmHg}$ for the 12 years group which was very close to the value for same age boys group (Table 3). All other age group for the girls were lying between 72.3 and $95.0 \mathrm{mmHg}$ (Table 3).

The minimum average diastolic pressure for age 1 group, when all the children were considered irrespective of gender, was $51.3 \pm 7.1 \mathrm{mmHg}$ and maximum average value observed for 11 year age group was $63.7 \pm 8.3$ mmHg. All other age groups' value was lying in between these two values (Table 1). For the boys, the minimum average systolic pressure was $49.7 \pm 6.1 \mathrm{mmHg}$ for 1 year age group and that of for the girls was $52.3 \pm 9.1 \mathrm{mmHg}$, slightly higher than the boys (Table 2 and Table 3).The maximum average diastolic pressure for the boys was 62.3 $\pm 7.6 \mathrm{mmHg}$ for the 12 age group. Very similar value of $62.3 \pm 9 \mathrm{mmHg}$ was observed for the girls but that was for 11 year age group (Table 2 and Table 3 ). But surprisingly, whether all the children considered irrespective of gender or considered according to gender, in each case diastolic pressure was low compared to the normal value $[14,15,16]$ for the all age group except 11 and 12 years (Table 1, Table 2 and Table 3). 
Table 1. Physical characteristics, Pulse rate and Blood pressure of 371 children (boys and girls) $(\mathrm{SD}=\mathbf{s t a n d a r d}$ deviation, $\mathrm{n}=$ number of participants, $F=$ female. $M=$ male)

\begin{tabular}{|c|c|c|c|c|c|c|c|c|c|c|c|c|c|}
\hline \multirow{3}{*}{ Age (yr) } & \multirow{2}{*}{\multicolumn{3}{|c|}{ number }} & \multirow{2}{*}{\multicolumn{2}{|c|}{ Height (cm) }} & \multirow{2}{*}{\multicolumn{2}{|c|}{ Weight (kg) }} & \multirow{2}{*}{\multicolumn{2}{|c|}{ Heart rate (beats/min) }} & \multicolumn{4}{|c|}{ Blood Pressure $(\mathrm{mm} / \mathrm{Hg})$} \\
\hline & & & & & & & & & & & & & \\
\hline & $\mathrm{n}=$ & $\mathrm{F}$ & $\mathrm{M}$ & mean & SD & mean & SD & mean & SD & mean & SD & mean & SD \\
\hline 1 & 24 & 09 & 15 & 60.7 & 5.5 & 6.5 & 0.8 & 153.5 & 6.2 & 69.1 & 8.3 & 51.3 & 7.1 \\
\hline 2 & 32 & 11 & 21 & 66.5 & 4.2 & 12.1 & 1.2 & 133.5 & 10.1 & 78.1 & 10 & 58.4 & 7.7 \\
\hline 3 & 32 & 12 & 20 & 72.4 & 6.6 & 13.7 & 1.3 & 135.5 & 7.8 & 81.3 & 8.5 & 61 & 7.9 \\
\hline 4 & 32 & 12 & 20 & 99.2 & 2.2 & 14.2 & 1.2 & 134.9 & 12.4 & 67.3 & 12.3 & 47.3 & 8.0 \\
\hline 5 & 32 & 09 & 23 & 104.2 & 2.4 & 15.8 & 1.4 & 133.4 & 7.9 & 78.7 & 7.8 & 58.4 & 8.7 \\
\hline 6 & 32 & 19 & 13 & 120.3 & 3.5 & 21.7 & 1.6 & 110.2 & 8.5 & 85.5 & 7.8 & 68.3 & 9.9 \\
\hline 7 & 32 & 10 & 22 & 123.8 & 1.7 & 23.3 & 1.2 & 90.7 & 6.3 & $\begin{array}{l}83.4 \\
\end{array}$ & 6 & 59.1 & 7.8 \\
\hline 8 & 33 & 12 & 21 & 125.6 & 1 & 25 & 1.3 & $\begin{array}{l}98.7 \\
\end{array}$ & 10 & 81.2 & 7.5 & 54.7 & 7.2 \\
\hline 9 & 32 & 08 & 24 & 127.1 & 1.3 & 26.6 & 1.5 & 83.9 & 18.3 & 74.4 & 15.2 & 50.9 & 8.9 \\
\hline 10 & 26 & 09 & 17 & 127.7 & 1.8 & 26 & 1.4 & 90.5 & 9.7 & 75.6 & 14.3 & 51.2 & 8.6 \\
\hline 11 & 32 & 11 & 21 & 129.8 & 1.6 & 30.2 & 1.1 & 75.9 & $\begin{array}{l}7.8 \\
\end{array}$ & 92.2 & 4.9 & 63.7 & 8.3 \\
\hline 12 & 32 & 06 & 26 & 135.7 & 2.4 & 31.3 & 1.3 & 71.6 & 9.5 & 95.9 & 5.6 & 61.2 & 7.5 \\
\hline
\end{tabular}

Table 2. Physical characteristics, Heart rate and Blood pressure of children (boys) (SD= standard deviation, n= number)

\begin{tabular}{|c|c|c|c|c|c|c|c|c|c|c|c|}
\hline \multirow{3}{*}{$\mathrm{n}$} & \multirow{3}{*}{ Age(yr) } & \multirow{2}{*}{\multicolumn{2}{|c|}{ Height(cm) }} & \multirow{2}{*}{\multicolumn{2}{|c|}{ Weight(kg) }} & \multirow{2}{*}{\multicolumn{2}{|c|}{ Heart rate (beats/min) }} & \multicolumn{4}{|c|}{ Blood Pressure (mm/Hg) } \\
\hline & & & & & & & & \multicolumn{2}{|c|}{ Systolic } & \multicolumn{2}{|c|}{ Diastolic } \\
\hline & & mean & SD & mean & SD & mean & SD & mean & SD & mean & SD \\
\hline 15 & 1 & 60.1 & 4.5 & 6.4 & 0.7 & 152.5 & 6.9 & 66.7 & 8.2 & 49.7 & 6.1 \\
\hline 21 & 2 & 67.1 & 4.1 & 12.1 & 1.2 & 131.7 & 11.3 & 78.6 & 9.1 & 59.1 & 7 \\
\hline 20 & 3 & 71.8 & 4.3 & 13.8 & 1.4 & 136.2 & 8 & 79 & 8.5 & 58.5 & 7.4 \\
\hline 20 & 4 & 99.9 & 1.9 & 14.5 & 1.3 & 132.7 & 12.1 & 66.2 & 12.5 & 47.7 & 7.7 \\
\hline 23 & 5 & 104.6 & 2.3 & 16.2 & 1.1 & 132.3 & 8 & 79.6 & 7.5 & 59.6 & 8.1 \\
\hline 13 & 6 & 120.1 & 3.8 & 21.7 & 1.6 & 109.2 & 8.6 & 84.6 & 8.7 & 66.1 & 8.7 \\
\hline 22 & 7 & 123.9 & 1.7 & 23.5 & 1.8 & 90.5 & 5.7 & 83.6 & 6.5 & 58.6 & 8.3 \\
\hline 21 & 8 & 125.8 & 1.1 & 25.3 & 1.4 & 98.9 & 11.4 & 82.5 & 8.4 & 56.2 & 7.4 \\
\hline 24 & 9 & 127 & 1.3 & 27 & 1.1 & 86.0 & 16.2 & 72.9 & 14.9 & 50 & 8.8 \\
\hline 17 & 10 & 128.1 & 1.7 & 26.3 & 1 & 91.2 & $\begin{array}{c}9.2 \\
\end{array}$ & 75.6 & 14.3 & 51.8 & 8.8 \\
\hline 21 & 11 & 129.5 & 1.3 & 30.1 & 1 & 76.5 & 8.4 & 92.8 & 4.6 & 61.9 & 7.5 \\
\hline 26 & 12 & 135.3 & 2.5 & 31.2 & 1.4 & 71.9 & 10.3 & 96.1 & 5.7 & $\begin{array}{l}62.3 \\
\end{array}$ & 7.6 \\
\hline
\end{tabular}

Table 3. Physical characteristics, Pulse rate and Blood pressure of children (girls) (SD= standard deviation, $n=$ number)

\begin{tabular}{|c|c|c|c|c|c|c|c|c|c|c|c|}
\hline \multirow{3}{*}{$\mathrm{n}$} & \multirow{3}{*}{ Age (yr) } & \multirow{2}{*}{\multicolumn{2}{|c|}{ Height(cm) }} & \multirow{2}{*}{\multicolumn{2}{|c|}{ Weight(kg) }} & \multirow{2}{*}{\multicolumn{2}{|c|}{ Heart rate(beats/min) }} & \multicolumn{4}{|c|}{ Blood Pressure $(\mathrm{mm} / \mathrm{Hg})$} \\
\hline & & & & & & & & \multicolumn{2}{|c|}{ Systolic } & \multicolumn{2}{|c|}{ Diastolic } \\
\hline & & mean & SD & mean & SD & mean & SD & mean & SD & mean & SD \\
\hline 09 & 1 & 60.8 & 7.6 & 6.7 & 0.9 & 155.1 & 4.5 & 72.3 & 7.9 & 52.3 & 9.1 \\
\hline 11 & 2 & 65.5 & 4.3 & 11.9 & 1.1 & 136.9 & 6.4 & 77.3 & 11.9 & 57.3 & 9.0 \\
\hline 12 & 3 & 73.4 & 9.3 & 13.7 & 1.4 & 134.8 & 7.4 & 85.0 & 6.7 & 65.0 & 6.7 \\
\hline 12 & 4 & 98.2 & 2.4 & 13.8 & 0.9 & 138.5 & 12.7 & 69.2 & 12.4 & 46.7 & 8.9 \\
\hline 09 & 5 & 103.0 & 2.2 & 14.9 & 1.8 & 136.4 & 7.1 & 76.7 & 8.6 & 55.6 & 10.1 \\
\hline 19 & 6 & 120.4 & 3.3 & 21.6 & 1.6 & 110.8 & 8.5 & 86.1 & 7.2 & 69.7 & 7.2 \\
\hline 10 & 7 & 123.6 & 1.5 & 23.0 & 1.1 & 91.2 & 8.1 & 83.0 & 4.8 & 60.0 & 6.7 \\
\hline 12 & 8 & 125.2 & 7.0 & 24.6 & 1.0 & 99.2 & 7.6 & 80.0 & 7.4 & 52.5 & 6.2 \\
\hline 08 & 9 & 127.3 & 1.5 & 25.5 & 2.1 & 77.5 & 23.5 & 78.7 & 16.4 & 53.7 & 9.2 \\
\hline 09 & 10 & 126.8 & 1.8 & 25.2 & 0.6 & 88.9 & 11.1 & $\begin{array}{l}75.6 \\
\end{array}$ & 15.1 & 50.0 & 8.6 \\
\hline 11 & 11 & 130.8 & 2.0 & 30.4 & 1.1 & 74.5 & 6.7 & 90.9 & 5.4 & $\begin{array}{ll}62.3 \\
\end{array}$ & 9.0 \\
\hline 06 & 12 & 137.2 & $\begin{array}{l}0.9 \\
\end{array}$ & 31.5 & 1.0 & 70.0 & 4.7 & 95.0 & 5.5 & 56.7 & 5.2 \\
\hline
\end{tabular}

Table 4. Correlation coefficient (r) among the different parameters (boys and girls combined), * significant ( $\mathbf{p}<$. 001)

\begin{tabular}{|c|c|c|c|c|c|c|}
\hline & age & ht & wt & heart rate & systolic & diastolic \\
\hline Age & 1 & $0.92 *$ & $0.97 *$ & $-0.90 *$ & 0.41 & 0.10 \\
\hline $\mathrm{Ht}$ & & 1 & $0.92 *$ & $-0.83 *$ & 0.34 & 0.11 \\
\hline $\mathrm{Wt}$ & & & 1 & $-0.90 *$ & 0.45 & 0.18 \\
\hline Heart rate & & & & 1 & -0.41 & -0.15 \\
\hline Systolic & & & & & 1 & 0.61 \\
\hline Diastolic & & & & & & 1 \\
\hline
\end{tabular}

Table 5. Correlation coefficient ( $r$ ) among the different parameters of boys * Significant $(\mathbf{p}<.001)$

\begin{tabular}{|c|c|c|c|c|c|c|}
\hline & age & ht & wt & heart rate & systolic & diastolic \\
\hline Age & 1 & $0.92^{*}$ & $0.97^{*}$ & $-0.89^{*}$ & 0.46 & 0.14 \\
\hline Ht & & 1 & $0.93^{*}$ & $-0.84^{*}$ & 0.38 & 0.13 \\
\hline Wt & & & 1 & $-0.90^{*}$ & 0.48 & 0.20 \\
\hline Heart rate & & & & 1 & -0.44 & -0.16 \\
\hline Systolic & & & & & & 1 \\
\hline Diastolic & & & & & & 0.61 \\
\hline
\end{tabular}

There is a general agreement supported by different studies that blood pressure rises with advancement of age [12]. Similar observations were also observed in the present study where both systolic and diastolic pressure increased as age advanced from 1 year to 12 years though relationships were not that much significant (Table 4, Table 5 and Table 6). The study supports the observation of Indian school children with the age group of 5 to 14 
years where both systolic and diastolic blood pressures increased with age in both sexes [16].

In the present study, maximum average heart rates were observed for the 1 year age group in both boys and girls as well as combined and the value went down gradually as age advanced (Table 1, Table 2 and Table 3). It was 152.5 \pm 6.9 beats/min for the boys and $155.1 \pm 4.5$ for the girls when the children were 1 year old. The values went down to $71.9 \pm 10.3 \mathrm{bpm}$ and $70 \pm 4.7 \mathrm{bpm}$ for boys and girls respectively as age advanced in both genders (Table 1 , Table 2 and Table 3). The heart rate was also went down as height and weight increases in both boys and girls group (Table 1, Table 2 and Table 3 ). These were highly reflected when co relationship was made among age, height, weight and heart rate (Table 4, Table 5 and Table 6, Figure 1, Figure 2 and Figure 3).

Table 6. Correlation coefficient $(r)$ among the different parameters of girls. $*$ Significant $(p<.001)$

\begin{tabular}{|c|c|c|c|c|c|c|}
\hline & age & ht & wt & Heart rate & systolic & diastolic \\
\hline Age & 1 & $0.90^{*}$ & $0.95^{*}$ & $-0.89^{*}$ & 0.3 & 0.04 \\
\hline $\mathrm{Ht}$ & & 1 & $0.90^{*}$ & $-0.81^{*}$ & 0.30 & 0.10 \\
\hline $\mathrm{Wt}$ & & & 1 & $-0.88^{*}$ & 0.41 & 0.18 \\
\hline Heart rate & & & & 1 & -0.34 & -0.16 \\
\hline Systolic & & & & & & 0.64 \\
\hline Diastolic & & & & & & \multicolumn{2}{c|}{1} \\
\hline
\end{tabular}

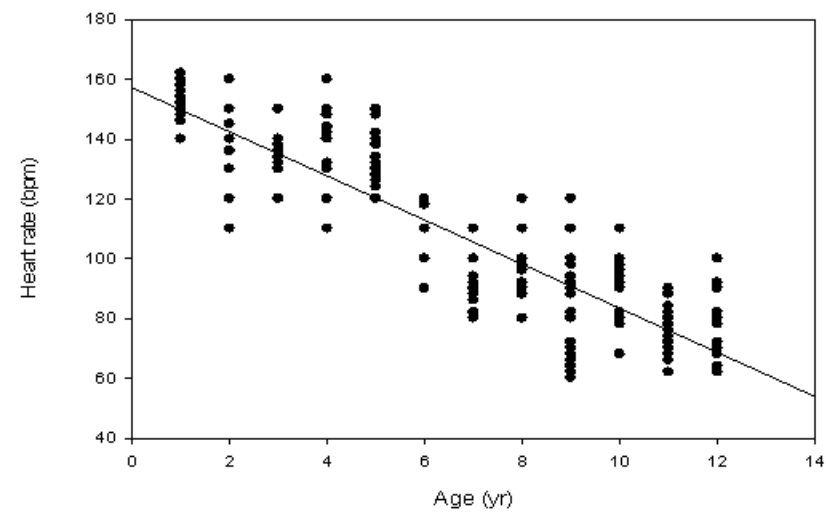

Figure 1. Effect of age on heart rate

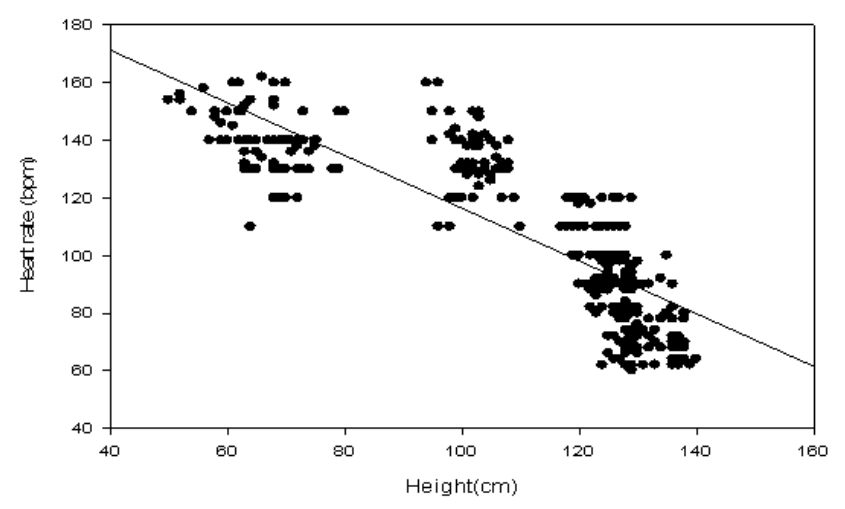

Figure 2. Effect of height on heart rate

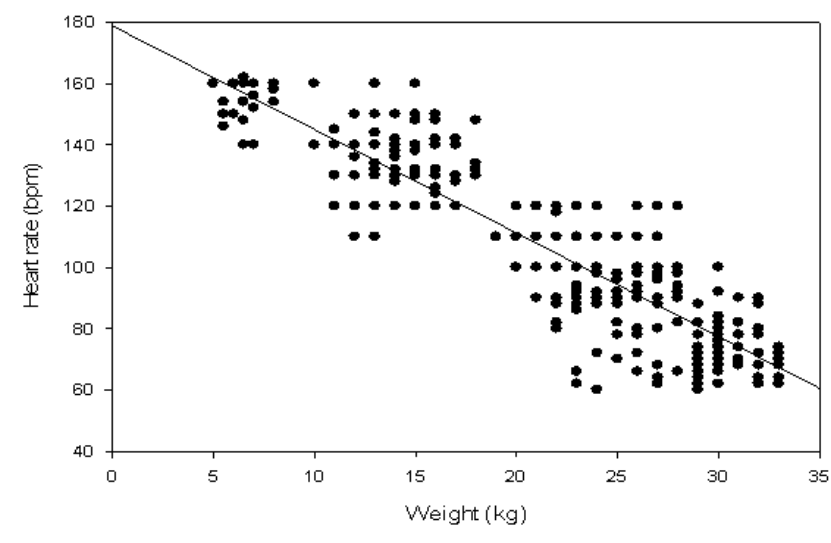

Figure 3. Effect of weight on heart rate

\section{Conclusion}

From the present study, it might be concluded that the Bangladeshi children possessed low blood pressure in comparison with other studies irrespective of boys and girls. The pulse rate decreased significantly as age, height and weight advanced towards higher values. The blood pressure also increased as age advanced but not significantly. The study needs further research in future.

\section{References}

[1] World Health Organisation, Geneva, 2009, Global Health RisksMortality and burden of disease attributable to selected major risks, available at www.who.int

[2] World Health Organisation, Geneva, 1985, Blood pressure studies in children, Technical Report Series, 715, available at www.who.int

[3] Din-Dzietham, R.,Liu, Y., Bielo,M.V., and Shamsa,F., High blood pressure trends in children and adolescents in national surveys, 1963 to 2002, Circulation, 116 (13): 1488-1496, 2007.

[4] Luepker, R. V.,Jacob, D.R.,Prineas, R.J., and Sinaiko,A.R., Secular trends of blood pressure and body size in a multi-ethnic, adolescent population: 1986 to 1996, Journal of Pediatrics, 134 (6) 668-674, 1999.

[5] Gidding, S.S., Bao, W.,Srinivasan, S.R., and Berenson,G.S., Effects of secular trends in obesity on coronary risk factors in children :the Bogalusa Heart study, Journal of Pediatrics, 127 (6): 868-874, 1995.

[6] McCarron, P., Smith, G.D., Okasha,M., and Secular,M., changes in blood pressure in childhood adolescence and young adulthood:systematic review of trends from 1948 to 1998, Journal of Human Hypertension, 16 (10): 677-689, 2002.

[7] Danaei,G., Finucane,M.M., and Lin,J.K., Global burden of metabolic risk factor chronic diseases collaborating group (blood pressure).National, regional and global trends in systolic blood pressure since 1980: systematic analysis of health examination surveys and epidemiological studies with 786 country-years and 5.4 million participants, Lancet, 377 (9765): 568-577,2011.

[8] Ribeiro J., Guerra,S., Pinto,A., Oliveira,J., Duarte,J., and Mota,J., Overweight and obesity in children and adolescents: relationship with blood pressure, and physical activity, Annals of Human Biology, 30 (2): 203-213, 2003.

[9] Mo-suwan, L., Tongkumchum, P., and Puetpaiboon, A., Determinants of overweight tracking from childhood to adolescence: a 5 year follow-up study based on the Boyd Orr cohort. American Journal of Clinical Nutrition, 67, 1111-1118, 1998.

[10] ISAK Manual, International Society for the Advancement of Kinanthropometry, www.isakonline.com, New Zealand, 2011, 
[11] Moss, A.J., Blood pressure in infants, children and adolescents (Medical Progress). Western Journal of Medicine, 134: 296-314, 1981.

[12] Ganong,W.F., Review of Medical Physiology, Tata McGraw-Hill edition, 22nd ed., Tata McGraw-Hill Publishing Company Limited, New Delhi, 2005.

[13] National Heart, Lung and Blood Institute, US Department of Health Services, 2011, available at http://www.nhlbi.nih.gov/about/contact/index.htm).
[14] Subhi, M.D., Blood pressure and hypertension in Iraqi primary school children, Saudi Medical Journal, 27 (4): 482-486, 2006.

[15] Rosaneli, C.F., Baena, C.P., Auler, F., Nakashima, A.T, NettoOliveira, E.R., Oliveira, A.B., Guarita-Souza, L.C., Olandoski, M., and Faria-Neto, J.R., Elevated blood pressure and obesity in Childhood: A cross-sectional evaluation of 4609 schoolchildren, Arquivos Brasileiros de Cardiologia, 2014, 29: 2014, available online at PubMed.

[16] Chadha, S. L.,, Tandon, R., Shekhawat, S., and Gopinath, N., An epidemiological study of blood pressure in school children (5-14 years) in Delhi, Indian Heart Journal, 51 (2): 178-182, 1999. 